\title{
Fuel production using membrane reactors: a review
}

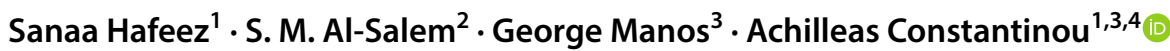

Received: 13 May 2020 / Accepted: 1 June 2020 / Published online: 8 June 2020

(c) The Author(s) 2020

\begin{abstract}
Population growth has led to higher consumption of fossil fuel, and subsequently to a major increase of greenhouse gases emissions to the atmosphere, thus inducing global warming. Fossil fuel supplies are depleting, and the price of these fuels is increasing. Moreover, there are concerns about related emissions of toxic pollutants such as sulphur dioxide and aromatic hydrocarbons. Here, we review alternative fuel technologies. We focus on how membrane reactors improve the existing production processes of renewable fuels. Advantages and environmental benefits of membrane reactors are compared to the conventional techniques. Membrane reactors have been applied successfully to improve biodiesel, hydrogen and FischerTropsch synthesis. Membranes help the conversion of products, whilst shifting the equilibrium of the reaction and reducing undesired by-products. Membrane reactors also overcome immiscibility issues that hinder conventional reactor processes. Overall, membrane reactors reduce cost and energy needed for the treatment of wastewater from fuel production.
\end{abstract}

Keywords Membrane reactors $\cdot$ Hydrocarbons $\cdot$ Fischer-Tropsch $\cdot$ Fuel $\cdot$ Energy

\section{Introduction}

The increasing demand for fossil fuels has led to a significant increase in greenhouse gases in the environment, resulting in concerns regarding future energy supply (Akhundi et al. 2019; Hafeez et al. 2020). Fossil fuels are the slowest growing source of energy, and their supplies are diminishing regularly (Barreto 2018). The price of fossil fuel resources is also rising due to their heightened demand. The increasing emissions of carbon dioxide $\left(\mathrm{CO}_{2}\right)$, sulphur dioxide $\left(\mathrm{SO}_{2}\right)$, hydrocarbons and volatile hydrocarbons from the burning of fossil fuels lead to significant amount of air pollution and global warming (Hafeez et al. 2020). In recent years

Achilleas Constantinou

constaa8@1sbu.ac.uk

1 Division of Chemical \& Petroleum Engineering, School of Engineering, London South Bank University, London SE1 OAA, UK

2 Environment \& Life Sciences Research Centre, Kuwait Institute for Scientific Research, P.O. Box: 24885, 13109 Safat, Kuwait

3 Department of Chemical Engineering, University College London, London WCIE 7JE, UK

4 Department of Chemical Engineering, Cyprus University of Technology, 57 Corner of Athinon and Anexartisias, 3036 Limassol, Cyprus there has been an interest in developing processes for clean alternative fuels for a more sustainable and greener environment. Renewable fuels such as biofuels, hydrogen $\left(\mathrm{H}_{2}\right)$, and the products from the Fischer-Tropsch process are now offered on a commercial scale to prevent the aforementioned problems.

Biodiesel has attracted much attention as an alternative, renewable and clean fuel. It is commonly derived from animal fat, vegetable oils and waste greases. Commonly used biomass for energy production includes agricultural waste, organic wastes, energy crops, sewage sludges and municipal green wastes (Aravind et al. 2020). It can be used as a transportation fuel because its physiochemical properties are similar to those of diesel ( $\mathrm{Lv}$ et al. 2020). First-generation biodiesel is produced from edible oils and food crops. The most common feedstock includes soybean oil, sunflower oil, palm oil, rapeseed oil and cottonseed oil. Second-generation biodiesel is produced from non-edible sources such as lignocellulose materials and non-edible oils which aids in reducing the demand for food crops. The use of these feedstocks is deemed to be more efficient and environmentally friendly as opposed to the feedstocks required to produce first generation biofuels. Third-generation biofuels use microalgae as the feedstock as it is considered more feasible when compared to the previously mentioned feedstocks. This is because they can produce substantially higher yields per area 
than the traditional crops. The two main algal cultivation systems widely used for biodiesel production are suspended and immobilised cultures (Mahlia et al. 2020).

$\mathrm{H}_{2}$ is also a viable option to be used as a clean alternative fuel. It can be produced from a range of renewable sources, such as the electrolysis of water, which enables using $\mathrm{H}_{2}$ as an energy storage, but also from methane or ethanol via steam reforming. The latter processes can potentially be carbon neutral provided the fuels come from biomasses (Bruni et al. 2019). Steam methane reforming (SMR) involves the reaction of methane and steam at a reaction temperature of $800{ }^{\circ} \mathrm{C}$ in the presence of a catalyst to produce syngas-a mixture of carbon monoxide (CO) and $\mathrm{H}_{2}$. The $\mathrm{CO}$ present in the syngas undergoes further reaction with steam in a water-gas-shift reactor to produce additional $\mathrm{H}_{2}$. Large-scale production in this way is $75-80 \%$ efficient and is a mature and well-established technology (Körner et al. 2015). $\mathrm{H}_{2}$ produced via the electrolysis of water $\left(\mathrm{H}_{2} \mathrm{O}\right)$, using electricity produced from renewable sources, can deliver a cleaner route for hydrogen production. The produced hydrogen can be used for energy storage or for transportation to places which require it. In addition, the hydrogen can be used in fuel cells for power generation for residential or automotive applications, or for load levelling and grid stability. $\mathrm{H}_{2}$ also serves as a feedstock to produce liquid fuels such as ammonia, methanol and dimethyl ethers (DME) (Giddey et al. 2019).

The Fischer-Tropsch process converts synthetic gas to hydrocarbons, which are further upgraded via water-gasshift reaction to produce $\mathrm{CO}_{2}$ and $\mathrm{H}_{2}$. Essentially, any carbon source can be used as the feedstock for the Fischer-Tropsch process to obtain alternative fuels. The Fischer-Tropsch process can produce a wide range of products which can then be upgraded to obtain the desired hydrocarbon fractions (Hafeez et al. 2018). The Fischer-Tropsch reaction is highly exothermic with reaction temperatures ranging between 300 to $350{ }^{\circ} \mathrm{C}$ under high pressures using iron-, cobalt- and ruthenium-based heterogeneous catalysts (Guettel et al. 2008). However, the high cost of ruthenium means that iron and cobalt are more frequently used. One limitation of using an iron-based catalyst is its inhibition by the side product of $\mathrm{H}_{2} \mathrm{O}$. On the contrary, its activity for the water-gas-shift reaction permits the use of $\mathrm{CO}_{2}$-rich gases or $\mathrm{H}_{2}$ exhausted syngas mixtures. Cobalt catalysts are found to be of higher activity and a longer catalyst lifetime when compared to iron catalysts. On the other hand, cobalt tends to be more expensive than iron (Guettel et al. 2008; Hafeez et al. 2020). A more detailed account of the mentioned fuel production routes and technologies can be found in Hafeez et al. $(2018,2020)$.

Membrane reactors have successfully been employed to intensify the renewable fuel production processes due to their advantages over conventional reactors. One of the most prominent advantages of the membrane reactor is that the reaction and separation aspects of the process are merged into one distinct unit. This precludes the need for additional separation and recycling units; as a result, the process becomes greener and environmentally sustainable. Furthermore, membrane reactors can enhance the conversion and selectivity of the reactions, decrease mass transfer limitations and have a greater thermal stability, as opposed to the conventional reactors (Zhang et al. 2018).

In this communication, we will highlight and elaborate upon the advantages of implementing membrane reactors for renewable fuel production when compared to conventional reactors and their environmental benefits. An in-depth review of membrane reactors for renewable fuel production will then be conducted to assess how conventional processes are intensified. This article is an abridged version of the chapter by Hafeez et al. (2020).

\section{Membrane reactors versus conventional systems for environmental applications}

A membrane reactor can be defined as a device that couples' reaction and separation within one single unit. The significant problems faced in the separation and purification of fatty acid methyl esters (FAME) from impurities have led to novel research into membrane reactors. This has been conducted in order to circumvent this costly problem, as well as optimise the production of biodiesel. According to the research carried out by Cao et al. (2008b) on methanol recycling in a membrane reactor to produce biodiesel, it was found that using an inorganic membrane could remove the desired constituents during the reaction from oil. The addition of a membrane also facilitates an increase in conversion, as the products permeate through the membrane and can be removed. This shifts the equilibrium in the forward reaction resulting in a higher yield of FAME, whilst reducing the amount of undesired side products. In addition, membrane reactors attain high conversion rates when compared to conventional ones due to the removal of undesired by-products (Baroutian et al. 2011).

The use of membrane reactors is more economically sustainable than conventional reactors. This is linked to the fact that such processes are intensified by combining the reaction and separation aspects in one unit. This can allow for the potential reductions in separation and recycling units, which would result in the process becoming less energy intensive. Therefore, efficiency increase is also anticipated. Furthermore, the intrinsic properties of inorganic membranes make them possess a high thermal threshold. Due to their thermal stability, membrane reactors can be used for reactions that are highly exothermic (Hafeez et al. 2020). 
The production of biodiesel via a catalytic membrane reactor is indisputably an environmentally friendly process when compared to the more conventional methods of producing biofuels. This is mainly due to its low energy consumption. The transesterification reaction is carried out under mild operating conditions of around $70{ }^{\circ} \mathrm{C}$, which is significantly lower than heterogeneous or supercritical transesterification. Dubé et al. (2007) reported that at around $100{ }^{\circ} \mathrm{C}$ using an alkaline catalyst, a very low catalytic activity is observed which only generated a FAME yield of $20 \%$. Furthermore, performing the transesterification reaction using heterogeneous catalysts requires reaction temperatures of between $180-200{ }^{\circ} \mathrm{C}$ (Di Serio et al. 2006) and 200 and $300{ }^{\circ} \mathrm{C}$ (Chen et al. 2007; Furuta et al. 2004; Jitputti et al. 2006). Moreover, the synthesis of heterogeneous catalysts often takes place at elevated temperatures ranging from 200 to $500{ }^{\circ} \mathrm{C}$ which makes the process energy-consuming and costly. This shows that less electricity is required for the membrane reactor by burning fossil fuels, which is detrimental to the welfare of the environment. Burning fossil fuels is notorious for producing undesired particulates into the air, such as carbon dioxide and sulphur dioxide; these emissions play a direct role in the production of acid rain which go on to have negative effects on plants, aquatic animals and damage infrastructures. With the use of membrane reactors, these harmful effects on the environment are minimised (Kampa and Castanas 2008). Nonetheless, catalytically active membranes are manufactured at milder temperatures (Guerreiro et al. 2006). The supercritical transesterification method of producing biodiesel is the most energy intensive requiring temperatures and pressures of $240-340{ }^{\circ} \mathrm{C}$ and 5.7-8.6 $\mathrm{MPa}$, respectively (Hawash et al. 2009). Comparing these conditions with those that are needed for transesterification in a catalytic membrane reactor, the conditions stated for supercritical transesterification are around 5 and 50 times greater, respectively (Shuit et al. 2012).

Typically, the production process requires the use of harmful solvents and chemicals which can have a detrimental effect on the environment. For the conventional production method, Marchetti et al. (2007) reported that the concentration for the alkaline catalyst is in the range of $0.5-1 \%$ $(\mathrm{NaOH})$. The concentration of the acid catalyst varied from $1-4 \%$, depending on the free fatty acid content in the oil (Narasimharao et al. 2007; Wang et al. 2006). Compared to the catalyst concentration in the conventional methods, the use of catalysts in the catalytic membrane reactor is lower at around $0.05 \%$ for the basic catalyst and $2 \%$ for the acid catalyst. In addition, both catalytically inert and catalytically active membranes are found to consume significantly lower amounts of methanol when compared to the supercritical technology which generated methanol-to-oil ratios of greater than 40 (Shuit et al. 2012).
The issue of large amounts of wastewater produced due to the separation and purification stages is an environmental alarm. The rise of wastewater effluents could possibly lead to an increase in the quantity of chemicals and solvents that are toxic to the environment (Shuit et al. 2012). However, if twenty million tonnes per year of biodiesel is produced (Licht and Agra 2007) with a density of $900 \mathrm{~kg} / \mathrm{m}^{3}$ (Knothe et al. 2005), the amount of wastewater that is produced by conventional separation methods would be 59 billion gallons. On the other hand, by using a membrane reactor, the amount of wastewater will significantly reduce to 12 billion gallons. Thus, a membrane reactor could make the purification step and the water washing procedure, superfluous as using a catalytically active membrane would not require water washing for purification. This in turn would drastically reduce the probability of chemicals and solvents harming the environment, due to the contaminants that comes with wastewater. Likewise, glycerol removal can be done via the use of a membrane reactor, separating it from the FAME phase during the reaction which makes the requirement of water washing all the more unnecessary (Shuit et al. 2012).

\section{Membrane reactors for renewable fuel production}

Typically, a membrane reactor encompasses four distinct parts. These are the design of the reactor (e.g. distributor, extractor or contactor), type of membrane used (e.g. porous, organic or inorganic), catalyst presence in the membrane, and finally, the reaction that is taking place inside the membrane reactor (Ertl et al. 2008). Furthermore, this type of reactor configuration has been proven to enhance the product yield and selectivity of the reaction (Marcano and Tsotsis 2002). The main benefit of using the combined membrane and reactor system is the fact that the capital and operating costs are significantly reduced because an intermediate separation step is not required (Marcano and Tsotsis 2002). Membrane technology has recently been applied to the production of renewable fuels due to its advantages over the conventional reactors.

\section{Membrane reactors for biofuel production}

Membrane technology is an economical and effective method for biofuels production, as well as offering high selectivity's and high surface-area-to-volume ratios (Hajilary et al. 2019). The most prominent role of the membrane for biodiesel production is to either remove the glycerol from the product (Guerreiro et al. 2006; Saleh et al. 2010) or to preserve the unreacted glycerides in the membrane (Baroutian et al. 2011; Dubé et al. 2007). The two notable methods of biodiesel production are the separation based on oil 
droplet size (Cao et al. 2008a, b) or by essentially using catalytic membranes (Guerreiro et al. 2006, 2010; Shao and Huang 2007). The former consists of a microporous membrane which is often a ceramic one.

Baroutian et al. (2010) investigated the recovery of methanol during the transesterification of palm oil in a ceramic membrane reactor using $\mathrm{TiO}_{2} / \mathrm{Al}_{2} \mathrm{O}_{3}$. The small size of the methanol molecules was able to pass through the membrane. The necessity to recover the methanol products is because it is an essential reactant for the transesterification process. In order to aid the process, the ceramic membrane unit was attached to a simple distillation unit to recover the methanol from the membrane permeate stream. A follow-up study performed by Baroutian et al. (2011) demonstrates the use of catalytic membranes. A packed-bed membrane reactor used a potassium hydroxide catalyst supported on palm shell activated carbon for biodiesel production. The results showed that the highest conversion of palm oil to biodiesel in the reactor was found at $70{ }^{\circ} \mathrm{C}$ utilising $157.04 \mathrm{~g}$ of catalyst per unit volume of the reactor and a cross flow circulation velocity of $0.21 \mathrm{~cm} / \mathrm{s}$. The biodiesel product obtained was compared with standard specifications based on the physical and chemical properties. It was concluded that high-quality palm oil diesel was obtained by using this membrane reactor configuration.

Catalytic membranes retain the ability to incorporate a catalyst depending on its formulations and functionality. A membrane without the incorporated catalyst can also be referred to as a catalytically inert membrane where the catalyst is added to the reactants, but not implanted inside the membrane (Buonomenna et al. 2010). The main catalytically inert membranes found in biodiesel production are the filtanium ceramic membranes (Cao et al. 2008a, b), Ti/ O2/A12O3 in ceramic membrane (Baroutian et al. 2010, 2011) and carbon membrane (Dubé et al. 2007) with the separation principle based on the oil droplet sizes. The pore sizes of these membranes can vary from 0.02 to $0.05 \mu \mathrm{m}$ (Baroutian et al. 2010). The catalysts used for the membranes without the incorporated catalyst include sulphuric acid (H2SO4) (Dubé et al. 2007) and potassium hydroxide/ sodium hydroxide solution $(\mathrm{KOH} / \mathrm{NaOH})$ (Baroutian et al. 2010). Firstly, a predetermined quantity of oil and a homogeneous mixture of methanol/KOH are passed into a mixing vessel for pre-mixing. The reaction mixture is then heated to the target reaction temperature, before being passed into the membrane reactor. The permeate stream is comprised of biodiesel, methanol, glycerol and catalysts (Baroutian et al. 2010; Dubé et al. 2007).

Hapońska et al. (2019) investigated membrane reactors (Fig. 1a) for biodiesel production using strontium oxide as a heterogeneous catalyst. The membrane reactor contained an immobilised heterogeneous catalyst as an alternative to the conventional homogeneous-based catalysed transesterification for biodiesel production. One of the more prominent issues with homogeneous catalysis is the catalyst recuperation and soap formation, and the utilisation of heterogeneous catalysts can overcome these issues. The performance of different membrane reactors with the addition of heterogeneous catalysts was compared to assess the effects on conversion. Amberlyst ${ }^{\circledR} 15$ with acid sites and different types of strontium oxide with basic sites were tested as heterogeneous catalysts. The results showed that the highest sunflower oil conversion (approximately 93\%) and the final FAME yield were achieved with strontium oxide and were easy to immobilise.

Luo et al. (2017) employed a novel polymer-based alkaline composite catalytic membrane (PACCM) for the transesterification of soybean oil with methanol in a flow-through mode. It was prepared with sodium silicate $\left(\mathrm{Na}_{2} \mathrm{SiO}_{3}\right)$ and $\mathrm{N}$-[(2-hydroxy-3-trimethylammonium) propyl] chitosan chloride reinforced into polypropylene non-woven fabric by nonsolvent induced phase separation. A conversion greater than $97 \%$ was obtained for the transesterification with the PACCMs in a membrane reactor using a methanol/soybean oil molar ratio of 9:1 and a residence time of $3913 \mathrm{~s}$ at a reaction temperature of $60{ }^{\circ} \mathrm{C}$. It was concluded that the PACCMs demonstrated a good catalytic activity and stability, and that it could withstand lower that $3 \mathrm{wt} \%$ water or lower than $1.5 \mathrm{wt} \%$ free fatty acid in the feedstock resulting in a conversion greater than $90 \%$.

Tian et al. (2020) prepared graphene oxide/polyethersulphone (PES) catalytic membranes, as heterogeneous acid catalysts, in the esterification of oleic acid (OA) with methanol, to produce biodiesel. The membrane was annealed at various temperatures to stimulate the catalytic activity and reusability. Heterogeneous acidic catalysts have several benefits when compared to homogeneous acid catalysts, such as lower corrosion, ease of separation and better economic feasibility. The results showed that the conversion of OA increased with increasing graphene oxide content in the membrane, and there were found to be no internal and external diffusion limitations regarding the catalytic activity. A conversion of greater than $85 \%$ was achieved with the membrane that annealed at $150{ }^{\circ} \mathrm{C}$.

Li et al. (2020) prepared poly(vinyl alcohol) hybrid catalytic membranes for the esterification via blending poly(vinyl alcohol) with solid catalyst, which was manufactured by grafting of acid ionic liquids (1-butysulphonate3-vinylimidazole hydrogen sulphate) onto natural nanofiberlike palygorskite (Fig. 1b). The addition of the solid catalyst was found to improve the thermal stability, mechanical strength and the membrane hydrophilicity. Moreover, the cross-linked poly(vinyl alcohol) hybrid catalytic membranes were desirable to remove water under mild conditions. The results showed that when a crossflow catalytic membrane reactor was used, the yield values were around $8.7 \%$. The 
(a)

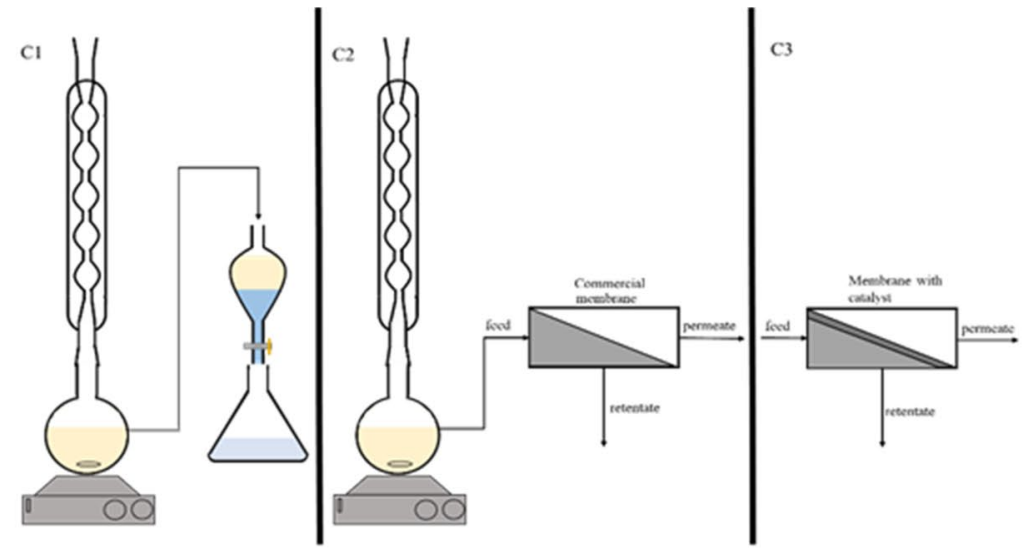

(b)

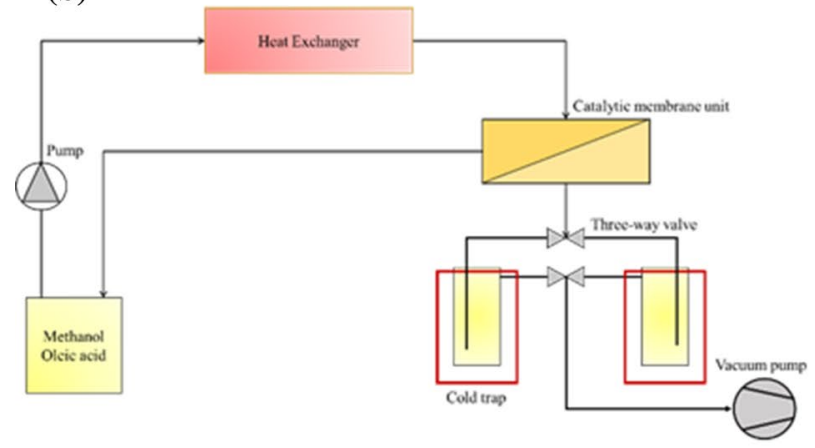

(c)

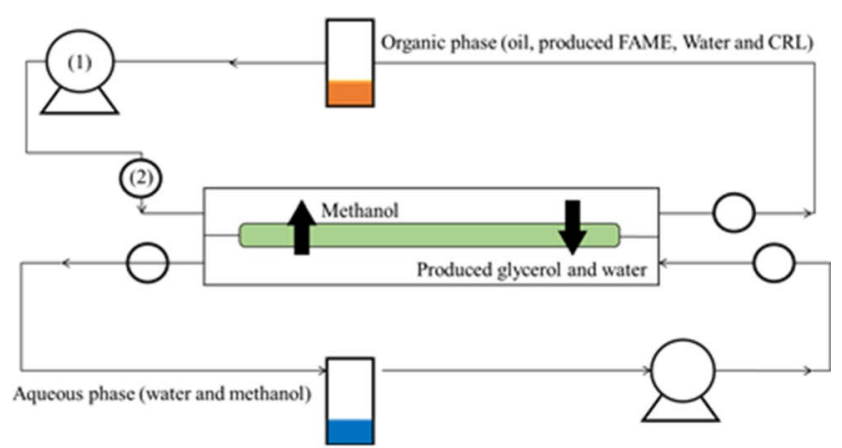

(d)

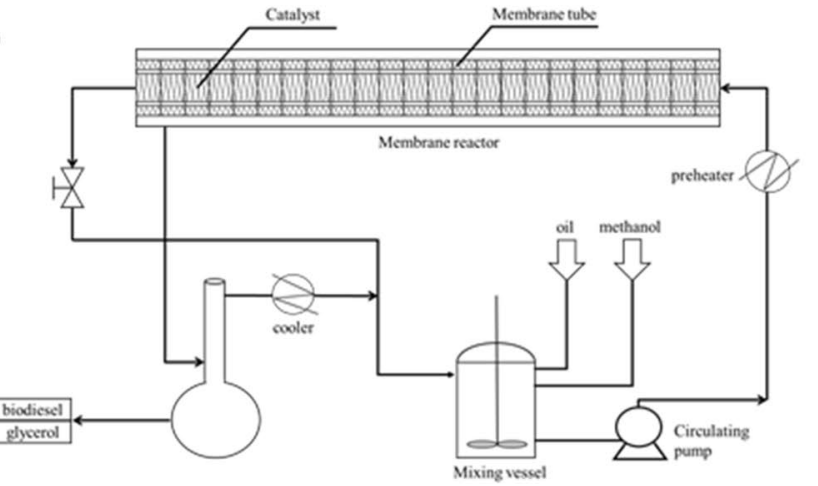

Fig. 1 (a) Configurations for the transesterification reaction: (C1) conventional reaction using the heterogeneous catalysts dispersed in the bulk solution followed by separate standard phases partition; (C2) reaction with the heterogeneous catalysts spread in the bulk solution coupled with in situ continuous filtration performed with a com-

yield could be enhanced by increasing the packing density of the membranes.

Oil droplets which have a pore size larger than the membrane pore size $(12 \mu \mathrm{m})$ (DeRoussel et al. 2001) are trapped on the retentate side and are subsequently recycled back to the mixing vessel (Cao et al. 2008b). The permeate stream can be separated into polar and non-polar phases. The nonpolar phase is made up of methanol, trace amounts of diglycerides and catalysts (Cao et al. 2008a, b). On the other hand, mercial membrane; (C3) reaction with the immobilised catalyst and a polymeric membrane; (b) schematic view of enzymatic membrane bioreactor; (c) schematic diagram of membrane reactor for biodiesel production; (d) catalytic membrane reactor process and membrane modules

the polar phase is comprised of glycerol, methanol, catalysts and biodiesel (Cao et al. 2008b). It has been observed that this type of catalytic membrane reactor is able to achieve an oil-to-biodiesel conversion of $\geq 90 \%$ for both $\mathrm{H}_{2} \mathrm{SO}_{4}$ and $\mathrm{KOH}$ catalysts (Dubé et al. 2007). In addition, using activated carbon as a catalyst support resulted in an increase in conversion by $93.5 \%$ (Rahimpour 2015). The methanol that permeates through the membrane is recycled back to the reactor to lessen the overall methanol-to-oil molar ratio (Cao 
et al. 2007). Methanol can be recycled back to the reactor by distilling the methanol from the non-polar phase and direct recycling of the polar phase (Rahimpour 2015).

Shuit and Tan (2019) performed a study on the feasibility of a single-step reaction and separation of palm fatty acid distillate to biodiesel via integrated pervaporation membrane reactor. The membrane reactor combined both reactor and membrane separator into a single unit. Esterification of palm fatty acid distillate with methanol was achieved in both batch reactors of the integrated pervaporation membrane reactor under the same reaction conditions. A reaction temperature of $135^{\circ} \mathrm{C}$, methanol-to-palm fatty acid distillate ratio of 20 , sulphonated multi-walled carbon nanotubes (s-MWCNTs) loading of $3 \mathrm{wt} \%$ and reaction time of 3,5 and $10 \mathrm{~h}$ were employed. At a reaction time of $10 \mathrm{~h}$, the polyimide membrane was able to remove $94.8 \%$ of the generated water from the reaction mixture. The thermally cross-linked polyimide membrane was found to be a hydrophilic membrane and exhibited negligible swelling in the reaction solvent, high thermal stability even at a high reaction temperature and pressure. The high removal percentage of water by the thermally cross-linked polyimide membrane has triggered an increment of $17.9 \%$ FAME yield in pervaporation membrane reactor as compared to the batch reactor.

Aghababaie et al. (2019) developed a two-phase enzymatic membrane reactor for the production of biodiesel from crude Eruca sativa oil (Fig. 1c). The use of the enzymatic membrane bioreactor with hydrophilic polyacrylonitrile membrane was found to enhance the yield of biodiesel product. Furthermore, the inactivation and inhibition effects of methanol and glycerol products were diminished with the application of the membrane bioreactor. An approximate yield of 100\% was obtained from Eruca sativa oil in a twophase enzymatic membrane reactor with polyacrylonitrile 100 and an organic phase flow rate of $40 \mathrm{~mL} / \mathrm{min}$ with a $40 \%$ initial water content in the organic phase.

Gao et al. (2017) developed a mathematical model based on the pore model of membrane (Fig. 1d) and the UNIQUAC model for liquid-liquid equilibrium for the production of biodiesel. They found that the oil content was significantly low and can typically be neglected in the practical operation when the conversion is less than $50 \%$. In addition, during the first half of the reaction the membrane system was in the FAME accumulation stage, subsequently switching to the membrane separation stage. When the reaction time was kept constant, the biodiesel yield increased with an increasing temperature. Despite this, the increasing trend of the biodiesel yield was constant, and the maximum yield was approximately the same. It was concluded that the membrane reactor can shift the equilibrium of transesterification to the side of the products by constantly removing the product stream.

\section{Membrane reactors for hydrogen production}

Recently, membrane reactors for $\mathrm{H}_{2}$ production have gained increasing attention due to their superiority over the conventional reaction systems. Typically, packed-bed membrane reactors have been used for $\mathrm{H}_{2}$ production. However, novel systems such as fluidised bed membrane reactors and micromembrane reactors have now been employed due to better mass and heat transfer (Gallucci et al. 2013). Furthermore, microporous silica $\left(\mathrm{SiO}_{2}\right)$ membranes have been extensively investigated as promising candidates for hydrogen separation because of the amorphous silica structures, which allow the permeation of helium and hydrogen but not the permeation of gas molecules with large molecular sizes (Meng and Tsuru 2016). Table 1 provides a summary of some of the studies which have demonstrated the use of membrane reactors for hydrogen production.

Myagmarjav et al. (2019) investigated the potential of silica membrane reactors (Fig. 2a) for use in the decomposition of hydrogen iodide to produce $\mathrm{CO}_{2}$ free $\mathrm{H}_{2}$ via the thermochemical water-splitting iodine-sulphur process. A simulation study was conducted to validate the experimental results and investigate important process parameters which could affect the membrane performance. The important process parameters which determined the membrane performance for hydrogen iodide decomposition were reaction temperature, total pressures on the feed and permeate sides

Table 1 Studies using membrane reactors for hydrogen synthesis

\begin{tabular}{|c|c|c|c|c|c|}
\hline Reference & Reactor type & Catalyst & Feed & Temperature $\left({ }^{\circ} \mathrm{C}\right)$ & Feed molar ratio \\
\hline Saidi and Moradi (2020) & $\mathrm{Pd}-\mathrm{Ag}$ membrane reactor & $\mathrm{Ni} / \mathrm{Al}_{2} \mathrm{O}_{3}$ & Glycerol & $350-500$ & 3 \\
\hline Anzelmo et al. (2017) & $\begin{array}{l}\text { Composite palladium-based membrane } \\
\text { reactor }\end{array}$ & Ni-based & $\mathrm{CH}_{4}$ & 400 & $3.5 / 1$ \\
\hline Ghasemzadeh et al. (2018) & Silica membrane reactor & $\mathrm{Cu} / \mathrm{ZnO} / \mathrm{Al}_{2} \mathrm{O}_{3}$ & $\mathrm{CH}_{3} \mathrm{OH}$ & $240-300$ & $1-3$ \\
\hline Itoh et al. (2020) & Tube-wall catalytic membrane reactor & $\mathrm{Ru}$ & Ammonia & 375 & 1.5 \\
\hline Kim et al. (2018) & Pd composite membrane reactor & $\mathrm{Ru} / \mathrm{Al}_{2} \mathrm{O}_{3}$ & $\mathrm{CH}_{4}$ & 500 & 3 \\
\hline Ma et al. (2016) & $\begin{array}{l}\text { Large-scale catalytic membrane reac- } \\
\text { tor }\end{array}$ & Commercial nickel-based & Ethanol & 350 and 450 & 1.5 \\
\hline
\end{tabular}


and the hydrogen iodide feed flow rate. The results showed that the conversion of hydrogen iodide decomposition can be enhanced by up to four times $(80 \%)$ or greater than the equilibrium conversion (20\%) at $400{ }^{\circ} \mathrm{C}$ by employing a membrane reactor equipped with a tubular silica membrane.

Arratibel et al. (2018) developed Pd-based doubleskinned membranes for $\mathrm{H}_{2}$ production in fluidised bed membrane reactors. These PdAg-supported membranes have a porous protecting layer to protect the surface of the membrane from particles in a fluidised bed membrane reactor. The results showed that an outstanding $\mathrm{H}_{2}$ permeance $(5 \times$ $10^{-6} \mathrm{~mol} \mathrm{~m}^{-2} \mathrm{~s}^{-1} \mathrm{~Pa}^{-1}$ ) and $\mathrm{H}_{2} / \mathrm{N}_{2}$ perm-selectivity (over 25,000 ) were measured at $400{ }^{\circ} \mathrm{C}$ and 1 bar of pressure difference. One membrane has been tested for more than 750 $\mathrm{h}$ in the presence of fluidised glass beads showing a decay in the perm-selectivity to approximately 5000, mainly due to sealing leakage. In addition, tests which involved binary mixtures were subject to mass transfer limitations towards the membrane because of the large $\mathrm{H}_{2}$ permeance of the membranes.

Tosto et al. (2020) studied the stability of pore-plated membranes (Fig. 2b) to produce hydrogen in fluidised bed membrane reactors. Palladium of approximately $20 \mu \mathrm{m}$ thickness was attained onto an oxidised porous stainless steel support. The stability of the membranes was examined for a maximum of $1300 \mathrm{~h}$ in gas separation mode (no catalyst) and a further $200 \mathrm{~h}$ to continuous fluidisation conditions. Permeances in the order of $5 \times 10^{-7} \mathrm{~mol} \mathrm{~s}^{-1} \mathrm{~m}^{-2} \mathrm{~Pa}^{-1}$ have been achieved for temperatures in a range between 375 and $500{ }^{\circ} \mathrm{C}$. During fluidisation, a small decrease in permeance is seen, because of the heightened external (bed-to-wall) mass transfer resistances. Furthermore, the water-gas-shift reaction was also conducted in a fluidised bed membrane reactor. It has been established that the selective $\mathrm{H}_{2}$ removal through the membranes resulted in $\mathrm{CO}$ conversions beyond the thermodynamic equilibrium (of conventional systems), demonstrating the benefits of membrane reactors in chemical conversions.

Saidi and Moradi (2020) investigated the production of hydrogen from waste glycerol, which is often a by-product of the biodiesel synthesis process. Glycerol steam reforming using membrane technology was modelled by taking into consideration the key transport phenomena, thermodynamic criteria and chemical process kinetics. A sensitivity analysis of operating conditions was made for key performance metrics such as glycerol conversion, hydrogen yield and hydrogen recovery. Glycerol conversion increases with increasing reaction temperature and pressure, although high feed molar ratio and sweep ratio have a decreasing effect. Hydrogen permeation and consequently hydrogen recovery enable with increasing sweep gas ratio and sweep gas temperature. Hydrogen recovery improves from 70 to $99 \%$ with an increasing temperature from 350 to $500{ }^{\circ} \mathrm{C}$ at a feed molar ratio of 3. Furthermore, hydrogen recovery improves from $50 \%$ to $71 \%$ with increasing sweep ratio from 0 to 20 at $350{ }^{\circ} \mathrm{C}$ and $1 \mathrm{bar}$.

Anzelmo et al. (2017) evaluated the performance of a composite palladium-based membrane reactor for the natural gas steam reforming reaction at low-temperature and pressure conditions for producing high-purity hydrogen. The membrane reactor consisted of a composite membrane having an approximate $13 \mu \mathrm{m}$ Pd layer deposited on a porous stainless steel support, fabricated via electroless plating and a commercial Ni-based catalyst. The composite membrane displayed an infinite ideal selectivity, $\mathrm{H}_{2} / \mathrm{He}$ and $\mathrm{H}_{2} / \mathrm{Ar}$, at transmembrane pressures of lower than $100 \mathrm{kPa}$ and a temperature of $400{ }^{\circ} \mathrm{C}$ at the beginning of the experimental testing. The reaction conditions of the steam reforming were $400{ }^{\circ} \mathrm{C}$, pressures of between 150 and $300 \mathrm{kPa}$, and a flow rate of $0-100 \mathrm{~mL} / \mathrm{min}$. The gas hourly space velocity (GHSV) and steam-to-carbon ratio (S/C) were kept continuous at $2600 \mathrm{~h}^{-1}$ and 3.5. The results showed that the optimal performance of the Pd-based MR is acquired at $400{ }^{\circ} \mathrm{C}, 300$ $\mathrm{kPa}$ and $100 \mathrm{~mL} / \mathrm{min}$ of sweep gas, generating a methane conversion of $84 \%$, hydrogen recovery of $82 \%$, and acquiring a pure hydrogen stream at the permeate side.

Furthermore, the performance of the membrane reactor was compared to a conventional fixed-bed reactor configuration at a reaction temperature of $400{ }^{\circ} \mathrm{C}$. It was found that the methane conversion was greater by $57 \%$ for the membrane configuration as opposed to the fixed-bed reactor and produced twice the amount of oxygen. Moreover, the membrane showed a near-infinite selectivity towards hydrogen permeation initially at pressures lower than $100 \mathrm{kPa}$. After 750 experimental hours, the ideal selectivity of hydrogen with respect to Ar dropped to 30. However, no CO was present in the permeate side for all the experimental operations, which shows that as the membrane slowly degraded, it retained the ability to produce $\mathrm{CO}$-free hydrogen for supplying a fuel cell or for industrial applications (Anzelmo et al. 2017).

Ghasemzadeh et al. (2018) developed an artificial neural networks (ANNs) model for the study of methanol steam reforming using a silica membrane reactor to produce hydrogen. Parameters such as a transmembrane pressure of between 0.5 and 1.5 bar, reaction temperature between 513 and $573 \mathrm{~K}$, GHSV between 3300 and $10,000 \mathrm{~h}^{-1}$ and steam/ $\mathrm{MeOH}$ molar ratio of 1-3 have been investigated during both experimental and modelling studies. This was done in order to analyse their effect on the silica membrane reactor performance with respect to a conventional reactor in terms of methanol conversion, $\mathrm{CO}$ selectivity, total hydrogen yield, hydrogen recovery, hydrogen and carbon monoxide compositions. The results showed that the reaction temperature was defined as the most effective operating parameter in the silica membrane reactor and the conventional reactor during the reaction. 


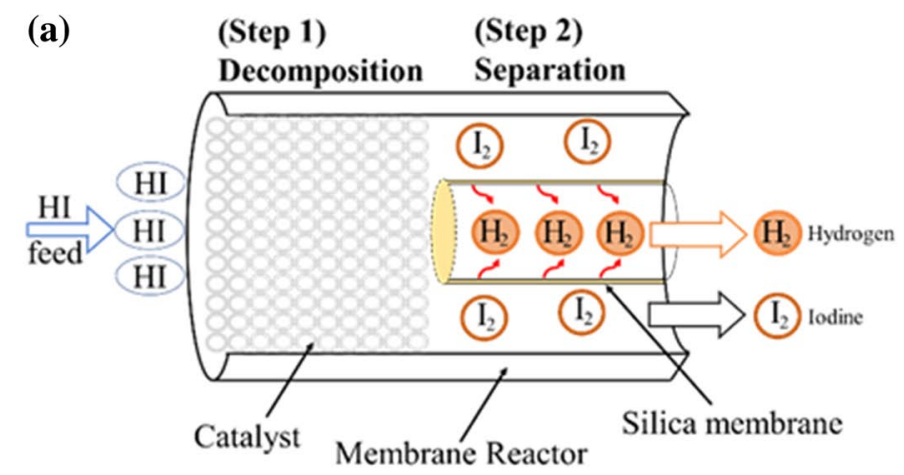

(b)

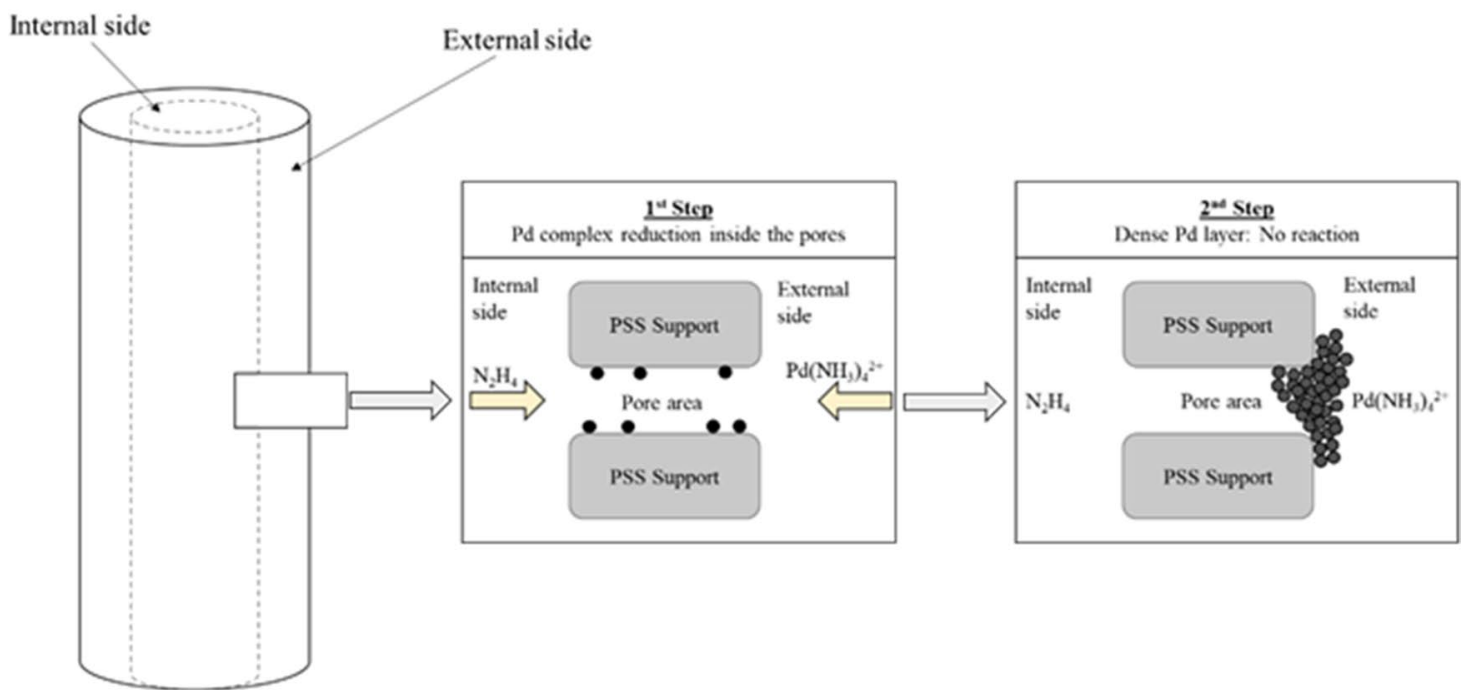

Membrane (Porous SS support)

(c)

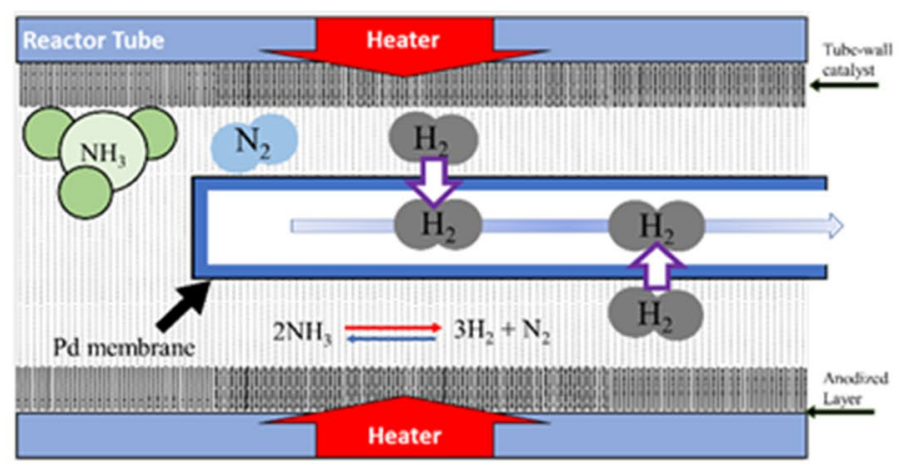

(d)

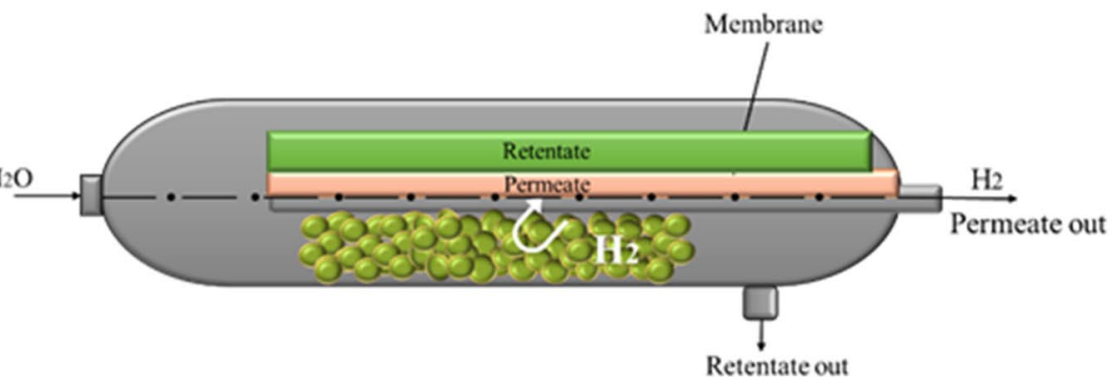


४Fig. 2 (a) Membrane reactor for hydrogen iodide decomposition; (b) pore plating technique; (c) tube-wall catalytic membrane reactor; (d) catalytic membrane reactor

Itoh et al. (2020) proposed a tube-wall catalytic membrane reactor (Fig. 2c) for hydrogen production by low-temperature ammonia decomposition. The ammonia decomposition reactor is kinetically limited at temperatures lower than $400{ }^{\circ} \mathrm{C}$, as opposed to thermodynamically limited. A tube-wall catalytic membrane reactor was developed which has the ability to decompose ammonia at temperatures below $400{ }^{\circ} \mathrm{C}$ whilst retaining a high conversion. Furthermore, the reactor displayed excellent heat transfer characteristics and almost achieved a $100 \%$ conversion for an ammonia feed of $10 \mathrm{~mL} / \mathrm{min}$, reaction temperature of $375^{\circ} \mathrm{C}$, a 2 - $\mu \mathrm{m}$-thick palladium composite membrane and a hydrogen removal from the decomposition side which led to a large kinetic acceleration.

Kim et al. (2018) studied the methane steam reforming reaction using a $\mathrm{Pd}$ composite membrane reactor packed with a commercial $\mathrm{Ru} / \mathrm{Al}_{2} \mathrm{O}_{3}$ catalyst under mild operating conditions, to produce hydrogen with $\mathrm{CO}_{2}$ capture. The methane steam reforming reaction, which was carried out at steam-to-carbon ratio (S/C) of 3.0, GHSV of $1700 \mathrm{~h}^{-1}$ and $773 \mathrm{~K}$, showed that methane conversion increased with the pressure difference and reached $79.5 \%$ at $\Delta \mathrm{P}=506 \mathrm{kPa}$. The gas composition monitored during the long-term stability test showed that the permeate side was composed of 97.8 vol $\% \mathrm{H} 2$, and the retentate side contained 67.8 vol $\% \mathrm{CO} 2$ with 22.2 vol\% $\mathrm{CH}_{4}$. When energy was recovered by $\mathrm{CH}_{4}$ combustion in the retentate streams, pre-combustion carbon capture was accomplished using the Pd-based composite membrane reactor.

Ma et al. (2016) investigated the steam reforming of ethanol in a large-scale catalytic membrane reactor (Fig. 2d) which was used to enhance the efficiency of the reaction via the in situ removal of hydrogen from the reactor module. Ethanol steam reforming was conducted under different conditions such as steam-to-carbon ratios, liquid hourly space velocities (LHSV), operating pressures and temperatures. Furthermore, a 1-D model and a 2-D computational fluid dynamics (CFD) model was created, validated experimentally and applied to investigate the parameters of this reaction. The catalytic membrane reactor was operated for 300 $\mathrm{h}$ showing $100 \%$ conversion of ethanol in all conditions and producing hydrogen with a purity of $99.9 \%$.

More recently, algal biomass has presented itself as a sustainable feedstock to produce liquid fuels and other energy products (Srivastava et al. 2020). Microalgae are photosynthetic microorganisms that can accomplish high oil contents. This oil is suitable for making biodiesel; thus, microalgae are believed to be a hopeful sustainable energetic resource that can lessen the dependence on fossil fuels (Peng et al.
2019; Gonçalves et al. 2013). Hydrothermal liquefaction is considered one of the most efficient thermochemical conversion techniques to produce high-quality biocrude oil that can be upgraded into a range of liquid fuels. Nevertheless, failure to identify practical uses for the hydrothermal liquefaction residual solids (biochar) potentially makes the process economically unviable particularly with low lipid algae. Ibrahim et al. (2020) investigated the hydrothermal liquefaction biochar of microalgae Galdieria sulphuraria to hydrogen under pyrolysis conditions in a membrane reactor which can selectively separate hydrogen from the reaction module. The hydrothermal liquefaction biochar pyrolysis was initially investigated using thermogravimetric analysis experiments and a fixed-bed reactor configuration. Batch membrane reactor pyrolysis experiments were subsequently performed using $\mathrm{Pd}_{77} \mathrm{Ag}_{23}$ hydrogen-selective membrane. This particular membrane was used during the pyrolysis of biochar because it resulted in the recovery of hydrogen in the permeate stream $(\sim 2$ times the hydrogen remaining in the retentate) and further enables the conversion of biochar to gaseous fuels. The retentate stream shows reduced $\mathrm{CO}$ and $\mathrm{CO}_{2}$ as well as increased $\mathrm{CH}_{4}$ content compared to pyrolysis conditions with no membrane.

Micromembrane reactors have recently been developed for hydrogen production. This is because membrane microreactors have enhanced mass and heat transfer (Constantinou et al. 2012, 2014) because of the shortened length of the microchannels, removal of mass transfer limitations (concentration polarisation) and heightened process intensification by integrating various process steps in small-scale process unit (Gallucci et al. 2013). Mejdell et al. (2009a, b, c) compared the performance of the same membrane in varying configurations. It was observed that by using the tubular configuration the extent of concentration polarisation is the limiting step for hydrogen permeation. On the other hand, the same membrane applied in a microreactor configuration, the concentration polarisation effect can be totally ignored (Mejdell et al. 2009c). Figure 8 shows a depiction of the microchannel reactor configuration used by Bredesen and co-workers (Mejdell et al. 2009b). The reactor is comprised of s-shaped microchannels which have a length of $13 \mathrm{~mm}$ and a section of $1 \mathrm{~mm} \times 1 \mathrm{~mm}$. The membranes used are $\mathrm{Pd}-$ based which have a thickness of less than $3 \mu \mathrm{m}$, and this type of membrane configuration is able to tolerate differential pressures of greater than $470 \mathrm{kPa}$.

\section{Membrane reactors for Fischer-Tropsch synthesis}

There are two types of membranes implemented in conventional Fischer-Tropsch reactors to improve their performance. Water separation membranes have the ability to selectively recover water molecules from the reaction module which is desirable as water has the highest product yield 
from the Fischer-Tropsch reaction. In doing so, the reaction equilibrium shifts towards the production of the hydrocarbons subsequently enhancing the conversion. Distributed feeding membranes are membranes which are selective towards $\mathrm{H}_{2}$ or $\mathrm{CO}$ and are used to control the concentration of the reactants along the reactor axis. This is advantageous as they allow a continuous $\mathrm{H}_{2} / \mathrm{CO}$ ratio to be maintained; as a result side reactions, such as methane formation, can be avoided as well as controlling the exothermicity of the reaction (Liuzzi et al. 2020).

A catalytic membrane has the capability to offer a defined reaction zone, whilst the reactants are forced through the membrane by means of a pressure gradient. High gas-liquid mass transfer rates can be obtained depending on the properties of the membrane, thus leading to higher volume specific production rates. In recent times, the products from the Fischer-Tropsch process are passed through a catalytic membrane which leads to an altered product distribution. Therefore, the motivating factors for implementing membrane technology to Fischer-Tropsch synthesis are: longer catalyst lifetime, higher product selectivity and higher specific production rates (Rohde et al. 2005b). The distributed feed of reactants through a membrane can enable better temperature control, and the selectivity of methane can be affected, by changing the $\mathrm{H}_{2} / \mathrm{CO}$ ratio. Since the activity and product selectivity rely strongly on the $\mathrm{H}_{2} / \mathrm{CO}$ ratio when utilising Co-based catalysts, distributed feeding can affect the gas phase composition optimistically (Rohde et al. 2005b).

Water is a side product formed during the Fischer-Tropsch process, and its accumulation in the gas phase can decrease the partial pressure of the reactants. This particular type of membrane configuration is highly useful because high water partial pressures can cause re-oxidation and a shorter catalyst lifetime. It has been observed that water can negatively affect the reaction rate and can encourage the formation of $\mathrm{CO}_{2}$ by the water-gas-shift reaction. By integrating the in situ removal of water membrane into the Fischer-Tropsch process, the rate of reaction can be enhanced and shifts the equilibrium in favour of $\mathrm{CO}$ production (Espinoza et al. 2000; Rohde et al. 2005a; Zhu et al. 2005).

A study conducted by Khassin et al. (2005) investigated the concept of forced-through flow membrane for Fischer-Tropsch synthesis by using thermally conductive contactor modules (plug-through contactor membrane, PCM). The synthesis gas enters through the internal void space and then passes through the membrane which has a thickness of $2.5 \mathrm{~mm}$. In order to enhance the thermal conductivity, copper can be employed during membrane production. It was noticed that PCMs can present lower pressure drops, high space-time yields at flat temperature profiles, larger reactor capacities, high gas-liquid mass transfer rates and low diffusive constraints. In addition, Bradford et al. (2005) utilised a monolith loop catalytic membrane reactor concept for Fischer-Tropsch synthesis to evaluate the performance of a $\mathrm{P} / \mathrm{Pt}-\mathrm{Co} / \gamma-\mathrm{Al}_{2} \mathrm{O}_{3}$ catalyst in a prototype, tubular catalytic membrane reactor and in a tubular, fixed-bed reactor. The synthesis gas was fed from the shell side to the alumina carrier material and passed through the membrane to the catalyst. The membrane allowed the produced hydrocarbons to be collected from the tube side.

Espinoza et al. (2000) conducted a series of permeation experiments with silicalite-1/ZSM-5 and mordenite (on a- $\mathrm{Al}_{2} \mathrm{O}_{3}$ /stainless steel support) under non-reactive conditions typical for Fischer-Tropsch $\left(200-300{ }^{\circ} \mathrm{C}\right.$ and $\left.2 \mathrm{MPa}\right)$. The results showed that mordenite membranes demonstrated high water fluxes $\left(\mathrm{PH}_{2} \mathrm{O}=2 \times 10^{-7} \mathrm{~mol} /\left(\mathrm{s} \mathrm{Pa} \mathrm{m}^{2}\right), 250{ }^{\circ} \mathrm{C}\right)$ and desirable permselectivities. Rohde et al. (2005a) carried out experiments in a packed-bed reactor with an integrated silica membrane. Although the membrane was found to show low permselectivities regarding the water under the Fischer-Tropsch reaction conditions, the shortcomings of the permselectivities can be overcome by the choice of $\mathrm{H}_{2}$ and $\mathrm{H}_{2} / \mathrm{CO}_{2}$ as the sweep gas. It was concluded that the increase in conversion of $\mathrm{CO}_{2}$ to long-chain hydrocarbons via the $\mathrm{CO}_{2}$ shift and Fischer-Tropsch process can be enhanced by the in situ removal of water, which results in higher product yields.

Alipour-Dehkordi and Khademi (2019) developed a onedimensional heterogeneous model for four configurations of a reactor, three microporous membrane reactors with $\mathrm{O}_{2}$ (O-MMTR), $\mathrm{CO}_{2}$ (C-MMTR) or $\mathrm{H}_{2} \mathrm{O}$ (H-MMTR) side-feeding strategy and one traditional reactor (i.e. multi-tubular fixed-bed reactor) (Fig. 3a), to explain the tri-reforming of methane to produce syngas. The effects of $\mathrm{CH}_{4}$ and $\mathrm{CO}_{2}$ conversion, $\mathrm{H}_{2} / \mathrm{CO}$ ratio and $\mathrm{H}_{2}$ yield were investigated by varying the side-feeding strategies. The results showed that the side-feeding strategies could be feasible, advantageous and flexible in terms of altering the membrane thickness and shell-side pressure for syngas production with $\mathrm{H}_{2} / \mathrm{CO}=2$ which is appropriate for methanol and Fischer-Tropsch process, and = 1.2 which is suitable for DME direct synthesis. Nonetheless, the syngas produced by the methane tri-reformer is only suitable for the methanol and Fischer-Tropsch synthesis under the base case conditions. Furthermore, the results indicated that the microporous membrane reactors have enhanced $\mathrm{CO}_{2}$ conversion, based on the $\mathrm{H}_{2} / \mathrm{CO}=1.2$. Therefore, these strategies are more environmentally friendly compared to the conventional reactor.

Shahhosseini et al. (2016) proposed an optimised packedbed membrane SMR tubular reactor (Fig. 3b) for sustainable $\mathrm{CH}_{4}$ conversion by implementing triple-objective optimisation model based on optimum $\mathrm{H} 2 / \mathrm{CO}$ ratio for low-temperature Fischer-Tropsch process. In this study, a one-dimensional pseudo-homogeneous model based on mass, energy 
(a)
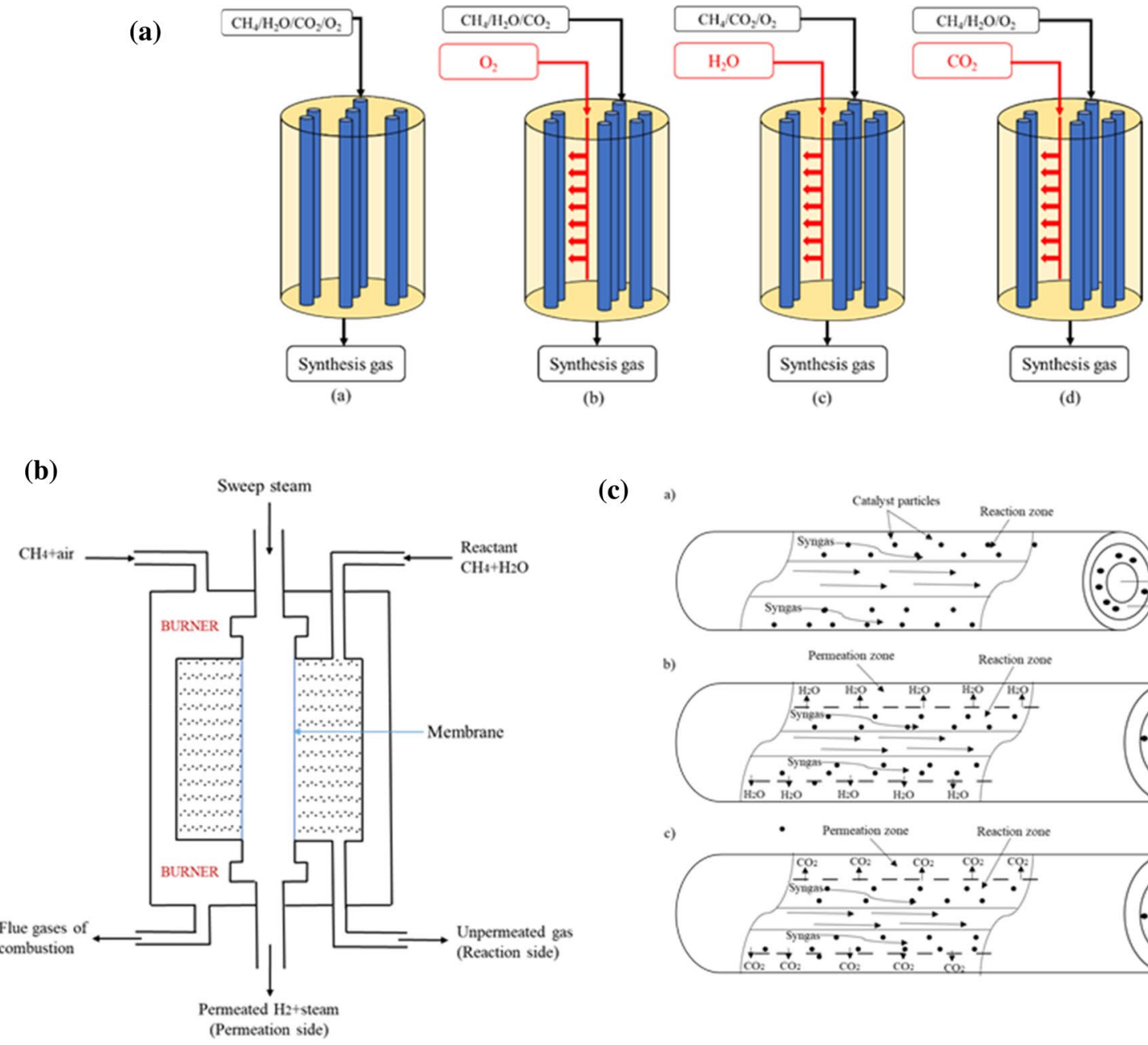

(c)

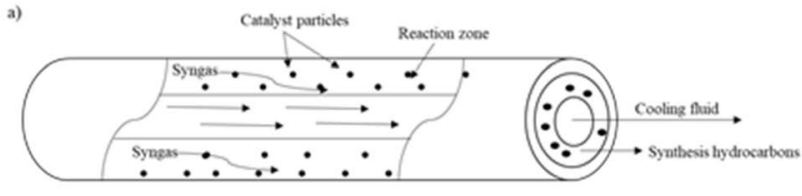

b)

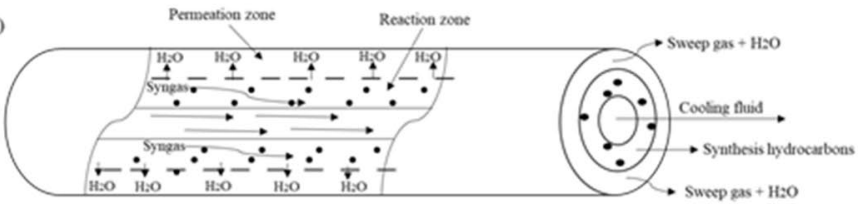

c) - Permentiog zone Reaction zone

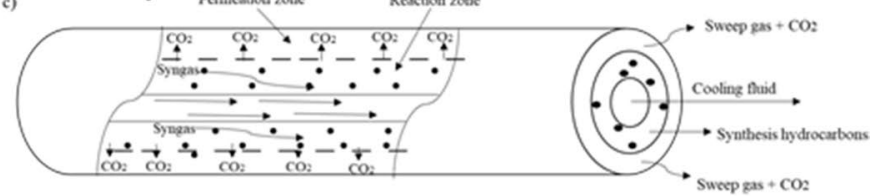

Fig. 3 (a) a. Methane tri-reformer, b. microporous membrane reactors with $\mathrm{O}_{2}$, c. microporous membrane reactors with $\mathrm{H}_{2} \mathrm{O}$ and d. microporous membrane reactors with $\mathrm{CO}_{2} ;(\mathbf{b})$ membrane reactor;

(c) Fischer-Tropsch membrane reactor, a. conventional reactor, b. membrane reactor for water removal, c. membrane reactor for $\mathrm{CO}_{2}$ removal

and momentum conservation laws is used to simulate the behaviour of a packed-bed membrane reactor for production of syngas by SMR. The results showed that the membrane reactor breaks the thermodynamic equilibrium restrictions among the reversible SMR reactions by the removal of $\mathrm{H}_{2}$ through the selective membrane. In doing so, an increase of $27.33 \%$ conversion can be achieved whilst enabling an improvement of $\mathrm{CO}$ production and decline of the $\mathrm{H}_{2} / \mathrm{CO}$ ratio from 5.5 to 2 at mild initial reaction conditions. The ability to control the $\mathrm{H}_{2} / \mathrm{CO}$ ratio in the membrane reactor makes this technology desirable for produce syngas for the low-temperature Fischer-Tropsch process.

Bellal and Chibane (2020) theoretically studied the Fischer-Tropsch reaction using an iron catalyst using different reactor configurations (Fig. 3c). It was concluded that the main results show that the membrane reactor

configuration is able to remove $\mathrm{H}_{2} \mathrm{O}$ or $\mathrm{CO}_{2}$ from the reaction zone as a result, affecting the reactant concentrations. This offers the opportunity to influence in situ the molar composition of $\mathrm{H}_{2} / \mathrm{CO}$ ratio and consequently the composition of the products mixture. The $\mathrm{H}_{2} / \mathrm{CO}$ ratio increased along the reactor in the case of carbon dioxide removal and decreased in the case of water removal, which resulted in a unique deviation of hydrocarbons distribution when compared to the conventional reactor. The most prominent advantage that should be noted here is the removal of $\mathrm{H}_{2} \mathrm{O}$ and $\mathrm{CO}_{2}$ from the product mixture can be attained entirely using a substantial amount of the sweep gas, which makes the range of obtained hydrocarbons clean and exempt of $\mathrm{H}_{2} \mathrm{O}$ or $\mathrm{CO}_{2}$. 


\section{Conclusion}

The various applications of membrane reactors in biofuels, hydrogen and the Fischer-Tropsch process have been presented in this review. Membrane reactors offer promising opportunities for process intensification to improve the alternative fuel production processes. They offer the combination of reaction and separation into a single unit, so eradicating the need for additional separation and recycling units. As a result, the fuel production process becomes less energy intensive which makes it greener and environmentally sustainable, as well as reducing capital costs. Furthermore, membrane reactors can enhance conversion and selectivity, reduce mass transfer limitations and have a greater thermal stability when compared to the conventional reactors. Membrane reactors have been implemented for the biofuel production process for the homogeneous and heterogeneous catalytic transesterification reactions. The membranes here are either used to separate and remove based on the oil droplet size or to be used as catalytic membranes. The membranes can be integrated with the catalyst or they can be utilised as catalytically inert membranes. The catalytically inert membranes often require the product stream to be further upgraded as it consists of catalysts, glycerol, methanol and FAME. As a result, the membranes with the integrated catalyst can often be regarded as more desirable as they require less separation and purification of the product stream. Membrane reactors for hydrogen production showcase the use of packed-bed membrane reactors, fluidised bed membrane reactors, micromembrane reactors and membrane bioreactors. Results show that fluidised bed membrane reactors demonstrate superiority over the packed-bed type and are therefore more likely to be implemented on an industrial scale. There are several membrane concepts which have been applied to enhance and intensify the Fischer-Tropsch process, such as distributed feeding and forced-through flow membranes. The latter has the potential to be applied for small- to medium-scale Fischer-Tropsch reactors. The large reactor capacities, innovative concepts for heat removal and a well-defined and fixed reaction zone ensure a safe and economically feasible process. Future applications of membranes can be investigated for processes such as the thermochemical treatment, the pyrolysis of biomass and plastic waste. Furthermore, research could be conducted to analyse the effects of fouling and stability of membranes, and how further modifications can be made to the production and development of novel membrane materials to enhance the renewable fuel production process. Furthermore, optimisation framework studies that incorporate membrane reactor technologies are very scant. Such work can be conducted to help understand the overall yield and process intensification strategies that could take place on industrial scale. Such mathematical platforms can also aid in conducting economic analysis that will render membrane technology more viable for the commercial market.

Acknowledgments The authors would like to thank London South Bank University, School of Engineering, for the $\mathrm{PhD}$ funding support.

Open Access This article is licensed under a Creative Commons Attribution 4.0 International License, which permits use, sharing, adaptation, distribution and reproduction in any medium or format, as long as you give appropriate credit to the original author(s) and the source, provide a link to the Creative Commons licence, and indicate if changes were made. The images or other third party material in this article are included in the article's Creative Commons licence, unless indicated otherwise in a credit line to the material. If material is not included in the article's Creative Commons licence and your intended use is not permitted by statutory regulation or exceeds the permitted use, you will need to obtain permission directly from the copyright holder. To view a copy of this licence, visit http://creativecommons.org/licenses/by/4.0/.

\section{References}

Aghababaie M, Beheshti M, Razmjou A, Bordbar A-K (2019) Two phase enzymatic membrane reactor for the production of biodiesel from crude Eruca sativa oil. Renew Energy 140:104-110. https:// doi.org/10.1016/j.renene.2019.03.069

Akhundi A, Habibi-Yangjeh A, Abitorabi M, Rahim Pouran S (2019) Review on photocatalytic conversion of carbon dioxide to valueadded compounds and renewable fuels by graphitic carbon nitride-based photocatalysts. Catal Rev 61:595-628. https://doi. org/10.1080/01614940.2019.1654224

Alipour-Dehkordi A, Khademi MH (2019) Use of a micro-porous membrane multi-tubular fixed-bed reactor for tri-reforming of methane to syngas: $\mathrm{CO} 2, \mathrm{H} 2 \mathrm{O}$ or $\mathrm{O} 2$ side-feeding. Int J Hydrogen Energy 44:32066-32079. https://doi.org/10.1016/j.ijhyd ene. 2019.10 .097

Anzelmo B, Wilcox J, Liguori S (2017) Natural gas steam reforming reaction at low temperature and pressure conditions for hydrogen production via Pd/PSS membrane reactor. J Membrane Sci 522:343-350. https://doi.org/10.1016/j.memsci.2016.09.029

Aravind S, Kumar PS, Kumar NS, Siddarth N (2020) Conversion of green algal biomass into bioenergy by pyrolysis: a review. Environ Chem Lett. https://doi.org/10.1007/s10311-020-00990-2

Arratibel A, Tanaka AP, Laso I, van Sint Annaland M, Gallucci F (2018) Development of Pd-based double-skinned membranes for hydrogen production in fluidized bed membrane reactors. $\mathrm{J}$ Membrane Sci 550:536-544. https://doi.org/10.1016/j.memsc i.2017.10.064

Baroutian S, Aroua MK, Raman AAA, Sulaiman NMN (2010) Methanol recovery during transesterification of palm oil in a $\mathrm{TiO} 2 /$ A12O3 membrane reactor: experimental study and neural network modeling. Sep Purif Technol 76:58-63. https://doi.org/10.1016/j. seppur.2010.09.020

Baroutian S, Aroua MK, Raman AAA, Sulaiman NM (2011) A packed bed membrane reactor for production of biodiesel using activated carbon supported catalyst. Bioresour Technol 102:1095-1102. https://doi.org/10.1016/j.biortech.2010.08.076

Barreto RA (2018) Fossil fuels, alternative energy and economic growth. Econ Model 75:196-220. https://doi.org/10.1016/j.econm od.2018.06.019 
Bellal A, Chibane L (2020) A new concept for control and orientation of the distribution of clean hydrocarbons produced by FischerTropsch synthesis over an industrial iron catalyst. React Kinet Mech Cat. https://doi.org/10.1007/s11144-020-01726-7

Bradford MC, Te M, Pollack A (2005) Monolith loop catalytic membrane reactor for Fischer-Tropsch synthesis. Appl Catal A-Gen 283(1-2):39-46. https://doi.org/10.1016/j.apcata.2004.12.032

Bruni G, Rizzello C, Santucci A, Alique D, Incelli M, Tosti S (2019) On the energy efficiency of hydrogen production processes via steam reforming using membrane reactors. Int J Hydrogen Energy 44:988-999. https://doi.org/10.1016/j.ijhydene.2018.11.095

Buonomenna M, Choi S, Drioli E (2010) Catalysis in polymeric membrane reactors: the membrane role. Asia-Pac J Chem Eng 5:26-34. https://doi.org/10.1002/apj.379

Cao P, Tremblay AY, Dube MA, Morse K (2007) Effect of membrane pore size on the performance of a membrane reactor for biodiesel production. Ind Eng Chem Res 46:52-58. https://doi.org/10.1021/ ie060555o

Cao P, Dubé MA, Tremblay AY (2008a) High-purity fatty acid methyl ester production from canola, soybean, palm, and yellow grease lipids by means of a membrane reactor. Biomass Bioenerg 32:1028-1036. https://doi.org/10.1016/j.biombioe.2008.01.020

Cao P, Dubé MA, Tremblay AY (2008b) Methanol recycling in the production of biodiesel in a membrane reactor. Fuel 87:825-833. https://doi.org/10.1016/j.fuel.2007.05.048

Chen H, Peng B, Wang D, Wang J (2007) Biodiesel production by the transesterification of cottonseed oil by solid acid catalysts. Front Chem Eng Chin 1:11-15. https://doi.org/10.1007/s1170 5-007-0003-y

Constantinou A, Barrass S, Pronk F, Bril T, Wenn D, Shaw J, Gavriilidis A (2012) CO2 absorption in a high efficiency silicon nitride mesh contactor. Chem Eng J 207:766-771. https://doi. org/10.1016/j.cej.2012.07.059

Constantinou A, Ghiotto F, Lam KF, Gavriilidis A (2014) Stripping of acetone from water with microfabricated and membrane gasliquid contactors. Analyst 139:266-272. https://doi.org/10.1039/ C3AN00963G

DeRoussel P, Khakhar D, Ottino JM (2001) Mixing of viscous immiscible liquids. Part 2: overemulsification-interpretation and use. Chem Eng Sci 56:5531-5537. https://doi.org/10.1016/S0009 $-2509(01) 00162-2$

Di Serio M, Ledda M, Cozzolino M, Minutillo G, Tesser R, Santacesaria E (2006) Transesterification of soybean oil to biodiesel by using heterogeneous basic catalysts. Ind Eng Chem Res 45:30093014. https://doi.org/10.1021/ie051402o

Dubé M, Tremblay A, Liu J (2007) Biodiesel production using a membrane reactor. Bioresour Technol 98:639-647. https://doi. org/10.1016/j.biortech.2006.02.019

Ertl G, Knözinger H, Schüth F, Weitkamp J (2008) Handbook of heterogeneous catalysis. Wiley, VCH Verlag $\mathrm{GmbH} \& \mathrm{Co}, \mathrm{KGaA}$, Weinheim

Espinoza R, Du Toit E, Santamaria J, Menendez M, Coronas J, Irusta S (2000) Use of membranes in Fischer-Tropsch reactors. Stud Surf Sci Catal. https://doi.org/10.1016/S0167-2991(00)80988-X

Furuta S, Matsuhashi H, Arata K (2004) Biodiesel fuel production with solid superacid catalysis in fixed bed reactor under atmospheric pressure. Catal Commun 5:721-723. https://doi.org/10.1016/j. catcom.2004.09.001

Gallucci F, Fernandez E, Corengia P, van Sint Annaland M (2013) Recent advances on membranes and membrane reactors for hydrogen production. Chem Eng Sci 92:40-66. https://doi. org/10.1016/j.ces.2013.01.008

Gao L, Xu W, Xiao G (2017) Modeling of biodiesel production in a membrane reactor using solid alkali catalyst. Chem Eng Process 122:122-127. https://doi.org/10.1016/j.cep.2017.09.019
Ghasemzadeh K, Aghaeinejad-Meybodi A, Basile A (2018) Hydrogen production as a green fuel in silica membrane reactor: experimental analysis and artificial neural network modeling. Fuel 222:114 124. https://doi.org/10.1016/j.fuel.2018.02.146

Giddey S, Badwal SP, Ju H (2019) Polymer electrolyte membrane technologies integrated with renewable energy for hydrogen production. Current trends and future developments on (Bio-) membranes. Elsevier. pp 235-259. https://doi.org/10.1016/B978-0-12813545-7.00010-6

Gonçalves AL, Pires JC, Simoes M (2013) Green fuel production: processes applied to microalgae. Environ Chem Lett 11:315-324. https://doi.org/10.1007/s10311-013-0425-3

Guerreiro L, Castanheiro J, Fonseca I, Martin-Aranda R, Ramos A, Vital J (2006) Transesterification of soybean oil over sulfonic acid functionalised polymeric membranes. Catal Today 118:166-171. https://doi.org/10.1016/j.cattod.2005.12.012

Guerreiro L, Pereira P, Fonseca I, Martin-Aranda R, Ramos A, Dias J, Oliveira R, Vital J (2010) PVA embedded hydrotalcite membranes as basic catalysts for biodiesel synthesis by soybean oil methanolysis. Catal Today 156:191-197. https://doi.org/10.1016/j.catto d.2010.04.046

Guettel R, Kunz U, Turek T (2008) Reactors for Fischer-Tropsch Synthesis. Chem Eng Technol 31:746-754. https://doi.org/10.1002/ ceat. 200800023

Hafeez S, Manos G, Al-Salem S, Aristodemou E, Constantinou A (2018) Liquid fuel synthesis in microreactors. React Chem Eng 3:414-432. https://doi.org/10.1039/C8RE00040A

Hafeez S, Al-Salem S, Constantinou A (2020) Membrane reactors for renewable fuel production and their environmental benefits. Membr Environ Appl. https://doi.org/10.1007/978-3-030-33978 $-410$

Hajilary N, Rezakazemi M, Shirazian S (2019) Biofuel types and membrane separation. Environ Chem Lett 17:1-18. https://doi. org/10.1007/s10311-018-0777-9

Hapońska M, Nurra C, Abelló S, Makkee M, Salvadó J, Torras C (2019) Membrane reactors for biodiesel production with strontium oxide as a heterogeneous catalyst. Fuel Process Technol 185:1-7. https://doi.org/10.1016/j.fuproc.2018.11.010

Hawash S, Kamal N, Zaher F, Kenawi O, El Diwani G (2009) Biodiesel fuel from Jatropha oil via non-catalytic supercritical methanol transesterification. Fuel 88:579-582. https://doi.org/10.1016/j. fuel.2008.09.007

Ibrahim AF, Dandamudi KPR, Deng S, Lin Y (2020) Pyrolysis of hydrothermal liquefaction algal biochar for hydrogen production in a membrane reactor. Fuel 265:116935. https://doi. org/10.1016/j.fuel.2019.116935

Itoh N, Kikuchi Y, Furusawa T, Sato T (2020) Tube-wall catalytic membrane reactor for hydrogen production by low-temperature ammonia decomposition. Int J Hydrogen Energ. https://doi. org/10.1016/j.ijhydene.2020.03.162

Jitputti J, Kitiyanan B, Rangsunvigit P, Bunyakiat K, Attanatho L, Jenvanitpanjakul P (2006) Transesterification of crude palm kernel oil and crude coconut oil by different solid catalysts. Chem Eng J 116:61-66. https://doi.org/10.1016/j.cej.2005.09.025

Kampa M, Castanas E (2008) Human health effects of air pollution. Environ Pollut 151:362-367. https://doi.org/10.1016/j.envpo 1.2007.06.012

Khassin AA, Sipatrov AG, Chermashetseva GK, Yurieva TM, Parmon VN (2005) Fischer-Tropsch synthesis using plug-through contactor membranes based on permeable composite monoliths. Selectivity control by porous structure parameters and membrane geometry. Top Catal 32:39-46. https://doi.org/10.1007/s1124 4-005-9258-Z

Kim C-H, Han J-Y, Lim H, Lee K-Y, Ryi S-K (2018) Methane steam reforming using a membrane reactor equipped with a Pd-based composite membrane for effective hydrogen production. Int $\mathbf{J}$ 
Hydrogen Energ 43:5863-5872. https://doi.org/10.1016/j.ijhyd ene.2017.10.054

Knothe G, Krahl J, Van Gerpen J (2005) The biodiesel handbook. AOCS Pres, Champaign

Körner A, Tam C, Bennett S, Gagné J (2015) Technology roadmaphydrogen and fuel cells. International Energy Agency (IEA), Paris

Li M, Zhang W, Zhou S, Zhao Y (2020) Preparation of poly (vinyl alcohol)/palygorskite-poly (ionic liquids) hybrid catalytic membranes to facilitate esterification. Sep Purif Technol 230:115746. https:// doi.org/10.1016/j.seppur.2019.115746

Licht F, Agra C (2007) World biodiesel markets: The outlook to 2010. Agra Informa Ltd, Kent, p 200

Liuzzi D, Fernandez E, Perez S, Ipiñazar E, Arteche A, Fierro JLG, Viviente JL, Tanaka DAP, Rojas S (2020) Advances in membranes and membrane reactors for the Fischer-Tropsch synthesis process for biofuel production. Rev Chem Eng. https://doi.org/10.1515/ revce-2019-0067

Luo Q, He B, Liang M, Kong A, Li J (2017) Continuous transesterification to produce biodiesel under $\mathrm{HTCC} / \mathrm{Na} 2 \mathrm{SiO} 3 / \mathrm{NWF}$ composite catalytic membrane in flow-through membrane reactor. Fuel 197:51-57. https://doi.org/10.1016/j.fuel.2016.12.089

Lv E, Dou T, Ding S, Lu J, Li Z, Yi W, Li J, Ding J (2020) Membrane dehydration-enhanced esterification for biodiesel production from a potential feedstock of Firmiana platanifolia Lf seed oil. Chem Eng Res Des 153:1-7. https://doi.org/10.1016/j.cherd.2019.10.020

Ma R, Castro-Dominguez B, Mardilovich IP, Dixon AG, Ma YH (2016) Experimental and simulation studies of the production of renewable hydrogen through ethanol steam reforming in a largescale catalytic membrane reactor. Chem Eng J 303:302-313. https ://doi.org/10.1016/j.cej.2016.06.021

Mahlia T, Syazmi Z, Mofijur M, Abas AP, Bilad M, Ong HC, Silitonga A (2020) Patent landscape review on biodiesel production: technology updates. Renew Sust Energ Rev 118:109526. https://doi. org/10.1016/j.rser.2019.109526

Marcano JGS, Tsotsis TT (2002) Catalytic membranes and membrane reactors. Wiley-VCH, Weinheim

Marchetti J, Miguel V, Errazu A (2007) Possible methods for biodiesel production. Renew Sust Energ Rev 11:1300-1311. https://doi. org/10.1016/j.rser.2005.08.006

Mejdell A, Jøndahl M, Peters T, Bredesen R, Venvik H (2009a) Effects of $\mathrm{CO}$ and $\mathrm{CO} 2$ on hydrogen permeation through a $\sim 3 \mu \mathrm{m} \mathrm{Pd} / \mathrm{Ag}$ $23 \mathrm{wt} \%$ membrane employed in a microchannel membrane configuration. Sep Purif Technol 68:178-184. https://doi.org/10.1016/j. seppur.2009.04.025

Mejdell A, Jøndahl M, Peters T, Bredesen R, Venvik H (2009b) Experimental investigation of a microchannel membrane configuration with a $1.4 \mu \mathrm{m} \mathrm{Pd} / \mathrm{Ag} 23 \mathrm{wt} \%$ membrane-effects of flow and pressure. J Membrane Sci 327:6-10. https://doi.org/10.1016/j.memsc i. 2008.11 .028

Mejdell A, Peters T, Stange M, Venvik H, Bredesen R (2009c) Performance and application of thin Pd-alloy hydrogen separation membranes in different configurations. J Taiwan Inst Chem E 40:253-259. https://doi.org/10.1016/j.jtice.2008.12.013

Meng L, Tsuru T (2016) Hydrogen production from energy carriers by silica-based catalytic membrane reactors. Catal Today 268:3-11. https://doi.org/10.1016/j.cattod.2015.11.006

Myagmarjav O, Tanaka N, Nomura M, Kubo S (2019) Module design of silica membrane reactor for hydrogen production via thermochemical IS process. Int J Hydrogen Energ 44:10207-10217. https ://doi.org/10.1016/j.ijhydene.2019.02.192

Narasimharao K, Lee A, Wilson K (2007) Catalysts in production of biodiesel: a review. J Biobased Mater Bio 1:19-30. https://doi. org/10.1166/jbmb.2007.002

Peng L, Fu D, Chu H, Wang Z, Qi H (2019) Biofuel production from microalgae: a review. Environ Chem Lett. https://doi.org/10.1007/ s10311-019-00939-0
Rahimpour M (2015) Membrane reactors for biodiesel production and processing. Membrane React Energy Appl Basic Chem Prod. https ://doi.org/10.1016/B978-1-78242-223-5.00010-8

Rohde MP, Unruh D, Schaub G (2005a) Membrane application in Fischer-Tropsch synthesis to enhance $\mathrm{CO}_{2}$ hydrogenation. Ind Eng Chem Res 44:9653-9658. https://doi.org/10.1021/ie050289z

Rohde MP, Unruh D, Schaub G (2005b) Membrane application in Fischer-Tropsch synthesis reactors-overview of concepts. Catal Today 106:143-148. https://doi.org/10.1016/j.cattod.2005.07.124

Saidi M, Moradi P (2020) Conversion of biodiesel synthesis waste to hydrogen in membrane reactor: theoretical study of glycerol steam reforming. Int J Hydrogen Energ 45:8715-8726. https:// doi.org/10.1016/j.ijhydene.2020.01.064

Saleh J, Tremblay AY, Dubé MA (2010) Glycerol removal from biodiesel using membrane separation technology. Fuel 89:2260 2266. https://doi.org/10.1016/j.fuel.2010.04.025

Shahhosseini HR, Farsi M, Eini S (2016) Multi-objective optimization of industrial membrane SMR to produce syngas for Fischer-Tropsch production using NSGA-II and decision makings. J Nat Gas Sci Eng 32:222-238. https://doi.org/10.1016/j.jngse .2016 .04 .005

Shao P, Huang R (2007) Polymeric membrane pervaporation. J Membrane Sci 287:162-179. https://doi.org/10.1016/j.memsc i. 2006.10 .043

Shuit SH, Tan SH (2019) Esterification of palm fatty acid distillate with methanol via single-step pervaporation membrane reactor: a novel biodiesel production method. Energ Convers Manage 201:112110. https://doi.org/10.1016/j.enconman.2019.112110

Shuit SH, Ong YT, Lee KT, Subhash B, Tan SH (2012) Membrane technology as a promising alternative in biodiesel production: a review. Biotechnol Adv 30:1364-1380. https://doi.org/10.1016/j. biotechadv.2012.02.009

Srivastava RK, Shetti NP, Reddy KR, Aminabhavi TM (2020) Biofuels, biodiesel and biohydrogen production using bioprocesses: a review. Environ Chem Lett. https://doi.org/10.1007/s10311-02000999-7

Tian F, Xu B, Li Y, Deng J, Zhang H, Peng R (2020) A highly active, readily synthesized and easily separated graphene oxide (GO)/ polyethersulfone (PES) catalytic membrane for biodiesel production. ChemistrySelect 5:1676-1682. https://doi.org/10.1002/ slct.201903846

Tosto E, Alique D, Martinez-Diaz D, Sanz R, Calles J, Caravella A, Medrano J, Gallucci F (2020) Stability of pore-plated membranes for hydrogen production in fluidized-bed membrane reactors. Int J Hydrogen Energ 45:7374-7385. https://doi.org/10.1016/j.ijhyd ene.2019.04.285

Wang Y, Ou S, Liu P, Xue F, Tang S (2006) Comparison of two different processes to synthesize biodiesel by waste cooking oil. J Mol Catal A-Chem 252:107-112. https://doi.org/10.1016/j.molca ta.2006.02.047

Zhang G, Jin W, Xu N (2018) Design and fabrication of ceramic catalytic membrane reactors for green chemical engineering applications. Engineering 4:848-860. https://doi.org/10.1016/j. eng.2017.05.001

Zhu W, Gora L, Van den Berg A, Kapteijn F, Jansen J, Moulijn J (2005) Water vapour separation from permanent gases by a zeolite-4A membrane. J Membrane Sci 253:57-66. https://doi.org/10.1016/j. memsci.2004.12.039

Publisher's Note Springer Nature remains neutral with regard to jurisdictional claims in published maps and institutional affiliations. 